Fecha de recepción: abril 2020

Fecha de aceptación: mayo 2020

Versión final: junio 2020

\section{Un aire de familia. Ley de Cine, recurrencias y aspectos comunes en el cine ecuatoriano del post-indigenismo}

Jorge Luis Serrano Salgado ${ }^{(1)}$

Resumen: A inicios de los años 80 el cine ecuatoriano registra un periodo de intensa actividad con producciones militantes de corte indigenista. 26 años después, tras aprobarse la primera ley de cine del país, se daría lugar, por el contrario, a un cine de ficción desinteresado por lo político, liviano y hedonista ¿Qué tienen en común las dos etapas? Que, tanto en una como en otra, quienes dominan la escena son cineastas originarios de las capas medias, de la pequeña burguesía ecuatoriana. Estos autores, mayoritariamente hombres, especialmente en el primer momento, practican de forma gregaria modas o tendencias que marcan cada generación. El diálogo que aparece entre las dos fases nos habla de prácticas sociales que se cultivan históricamente en una sociedad fracturada en su diversidad.

Palabras clave: Cine ecuatoriano - Industria cultural - Pequeñoburgués - Gregarismo Comunidad práctica.

[Resúmenes en inglés y portugués en la página 218]

(1) Sociólogo. Maestro en Comunicación por Flacso, Quito. Ha sido Director Ejecutivo del Consejo Nacional de Cinematografía del Ecuador (Cncine), Viceministro de Cultura y Patrimonio del Ecuador y Agregado Cultural del Ecuador en Francia. Docente universitario. Articulista. Doctorante en Comunicación por la Universidad Nacional de La Plata.

\title{
Introducción
}

En la breve historia del cine ecuatoriano hay dos momentos fuertes a los que se hace alusión en el subtítulo: el indigenismo cinematográfico de los años 80 y la ley de cine de 2006. Los dos reflejan, con precisión y exactitud, las coyunturas de la sociedad a las cuales corresponden. Porque los períodos de crecimiento de la producción fílmica local coinciden con etapas de expansión de la riqueza nacional, un crecimiento de la clase media urbana fruto del fortalecimiento de la economía primario exportadora y, en lo político, coinciden con momentos progresistas y renovadores, el primero, abruptamente interrumpido, mucho más breve y frágil que el segundo, siendo ambos propicios, de formas asimétricamente parecidas, a la implementación de políticas de fomento propias de la gestión pública. 
Es precisamente el universo simbólico de esa capa media fortalecida el que se despliega y domina en las narrativas propuestas en los dos momentos. Una suerte de gregarismo andino los cobija a ambos, con relatos más implicados políticamente en el primer caso, en concordancia con el credo militante de sus autores, muy en boga en la época y, en el segundo, se despliega una narrativa más hedonista e individualista, sin compromiso político evidente en la ficción y con un fuerte discurso a favor de la memoria desde el documental, -haciendo evolucionar así el relato político de sus antecesores- y siendo, en los dos casos, obras de realizadores/as integrantes en su mayoría de la clase media o pequeño-burguesía ${ }^{1}$ ecuatoriana.

Resulta importante arrancar con esta constatación sociológica porque, entre otras cosas, la demanda y necesidad de recursos financieros propios para realizar un film determina exclusiones de partida. La extracción social a la que se le hace posible enfrentar, en cierta medida, inversiones más o menos cuantiosas en esta rama de la industria cultural, sin apoyos públicos, deja de lado actores históricamente subalternos, sea por razones de clase o de etnia, junto a todo lo que ello significa particularmente en Ecuador. Dichos sujetos sociales carecen de una mayor presencia y visibilidad en el abanico de propuestas narrativas y discursivas surgidas en los dos momentos, no por falta de talento sino porque no se dispone de la formación, de los contactos o de los medios económicos para emprender, por sí solos, proyectos de envergadura que puedan insertarse con posibilidades de éxito o protagonismo dentro del mercado doméstico y/o en el circuito internacional de festivales, espacios estos últimos fuertemente formateados por narrativas y dramaturgias que, en fondo y forma, responden a una estética y una ética dominante en el momento. Ahora bien, aquí se hace una primera parada autocrítica de la política pública implementada al aplicar la ley de 2006 porque la misma no resolvió ni alteró dicha tendencia sino que, por el contrario, la acentuó, aunque hayan existido tímidos intentos por incorporar reflexiones y espacios a favor de la diversidad impulsados, fundamentalmente, por las nociones de plurinacionalidad e interculturalidad presentes en el marco constitucional vigente en Ecuador desde 2008. De cualquier forma, más allá de lo local, la revolución tecnológica digital ha jugado un rol determinante en la democratización de la producción haciendo accesibles herramientas audiovisuales a actores históricamente excluidos globalmente aunque, contradictoriamente, la misma revolución haya restringido dramáticamente las posibilidades de circulación en todas las ventanas a través de la imposición de términos unilaterales por parte de las corporaciones monopólicas del nuevo mundo digital.

Vale mencionar además que, fuera de este marco y durante algunos años, desde el campo de la distribución pirata, articulada en torno a soportes físicos de $d v d$ o blu-ray, se produce un importante volumen de consumo de contenidos nacionales que podrían ser catalogados como expresión de un audiovisual popular ecuatoriano, en tanto sus realizadores provienen mayoritariamente de sectores proletarios del campesinado montubio de la costa, indígena de la sierra o de sectores marginales de Guayaquil. Sin embargo, esta forma de producción si bien sorprende por su productividad y dinámica autónoma, en tanto se financia a través de mecanismos privados sui generis, al margen de las políticas públicas, no ha estado en condiciones de disputar la hegemonía cultural que predomina en el gusto de las mayorías, de la cual, además, es claramente subsidiaria y ocupa un espacio secundario 
dentro de un negocio igualmente marginal perseguido por el marco jurídico adoptado por Ecuador por presión de la OMC, en materia de propiedad intelectual, desde 1998.

\section{Los ' 80}

En agosto de 1979 Ecuador retorna a la vida democrática con la elección del joven abogado guayaquileño, de 38 años de edad, Jaime Roldós Aguilera, quien, apenas un año y medio después de asumir el poder, moriría junto a su esposa y una comitiva de 8 personas en un oscuro accidente aviatorio que no ha sido esclarecido hasta la fecha. El multipremiado documental de Manolo Sarmiento y Lisandra Rivera, titulado precisamente $\mathrm{La}$ muerte de Jaime Roldós (2013), explora a través de documentos desclasificados durante el rodaje la hipótesis de que la tragedia sea una consecuencia desconocida de la aplicación del Plan Cóndor, cuyos sangrientos hilos habrían llegado así hasta Ecuador. Dicha probabilidad nunca fue considerada por la breve, endeble y tortuosa investigación oficial y en ese trabajo de pesquisa periodística y documental así como en la utilización de material de archivo radica uno de los mayores intereses y fortalezas de la obra estrenada en 2013, 32 años después del siniestro. El documental aborda hechos sucedidos durante los años 80 y no es el único caso pues otros títulos realizados bajo el paraguas de la ley de cine de 2006 revisitan aquellos años para dar piso, junto a otros factores, cada uno a su manera, al "aire de familia" que da título al texto.

Durante los años 70 los ecuatorianos vivimos algo que fue común en Sudamérica, una dictadura, conocida ingenua y coloquialmente entre nosotros como "dictablanda" quizás porque, bajo el mando inicial del general Guillermo Rodríguez Lara, aquel gobierno no reprimió brutalmente a la sociedad como lo hacían las sangrientas dictaduras del cono sur. Este militar, de talante nacionalista apodado Bombita, fue quien administró el boom petrolero que, entre otras cosas, hizo viable el crecimiento vertical de Quito, sentando las bases para la transformación o tránsito de Ecuador de una sociedad rural hacia otra urbana. A finales de los años 70 Bombita fue defenestrado por un triunvirato virulento y fascista que es el que alinea el país al Plan Cóndor, negociando secretamente su adhesión al mismo con los militares del cono sur lo cual es, precisamente, develado por el documental La muerte de Jaime Roldós.

Bajo aquel contexto umbroso, que se cierne y sobrevuela acechante sobre la renaciente democracia ecuatoriana de los años ochenta, que está tan bien descrito y revivido en la obra de Sarmiento y Rivera, tiene lugar una etapa muy productiva del cine nacional. Si bien los pioneros habían dejado sus rastros a lo largo del siglo XX, la cinematografía ecuatoriana arranca como movimiento generacional a finales de los años setenta, cuando se retoma la vida democrática. Por primera vez no hablamos de individuos aislados sino de toda una generación cuyo impulso se refleja en el número de producciones hechas durante aquellos años, en la cantidad de festivales alrededor del mundo en los que participa nuestra joven cinematografía, en la creación de la Asociación de Cineastas del Ecuador, Asocine, en 1977, hoy inactiva, y en el número de estrenos de películas de ficción y documental 
gracias, entre otras cosas, a una incipiente política de incentivo tributario implementada durante el breve gobierno de Roldós.

Los cineastas ecuatorianos de los ochenta adoptaron tardíamente los principios del movimiento del Nuevo Cine Latinoamericano de los años sesenta que, bajo el influjo capital de la revolución cubana, como respuesta ante la hiriente cantidad de dictaduras de línea fascista presentes a lo largo de América Latina, veía en el séptimo arte una herramienta de acción política directa para denunciar la realidad social y despertar la conciencia ciudadana con la idea de que los espectadores salgan de la sala a transformarlo todo. Sin embargo, no porque el sujeto o tema de las obras fuesen las condiciones de vida del pueblo ecuatoriano aquellas eran películas populares. Dicho en otras palabras, no se trataba de un cine popular desde el punto de vista del mercado local, o mejor dicho del consumo que predominaba, y predomina, en el mismo.

A pesar de que Ecuador fue el primer país sudamericano en regresar a la vida democrática tras las dictaduras de los años setenta, se trataba de una sociedad atravesada por enormes e hirientes desequilibrios e inequidades sociales, lo cual, sumado al mencionado influjo de las cinematografías latinoamericanas más potentes, explica la existencia de una generación de cineastas altamente politizados y con frecuencia dogmáticos. Su doctrina de acción se cobijaría fundamentalmente bajo la figura rectora del indigenismo ${ }^{2}$ en un contexto militante que, aquellos años, también incluye a la universidad pública, espacio al cual están vinculados varios de los cineastas de esta generación.

Por tal razón en el país de esos años no se concebía hacer cine si no era para denunciar la realidad, para retratar el injusto estado de las cosas y, especialmente, para denunciar los rastros y evidencias de una sociedad colonial que mantenía en estado abyecto a las grandes mayorías indígenas del país. Cualquier propuesta que se alejase de ese canon era castigado con furia intelectual, por traicionar aquella disciplina colectiva generacionalmente practicada en torno al hecho cinematográfico que tuvo en el fundador de la Cinemateca Nacional, Ulises Estrella, a uno de sus principales promotores. Tal sería el caso del ingenuo largometraje Dos para el Camino (1981) de Jaime Cuesta que fue tachado de superfluo y de "hacerle el juego al cine de evasión", el más grave pecado que un cineasta ecuatoriano podía cometer entonces. Pero mientras Dos para el camino conquistaba las masas "cinefílicas" del país, ya que se trataba del primer film ecuatoriano protagonizado por el comediante Ernesto Albán ${ }^{4}$, convirtiéndose en la excepción de aquellos años al hacer, según su director y productor Jaime Cuesta, más de un millón de espectadores en salas comerciales dentro de un circuito provincial y cantonal de cines y teatros hoy extinto, las obras indigenistas dominantes, mayoritariamente documentales, eran vetadas en esas mismas salas porque éstas se negaban abiertamente a proyectar "cine de indios"

Más allá de los debates necesarios sobre las formas posibles de la censura, con el tiempo nace la siguiente pregunta ¿qué hacían esos directores mestizos, en su mayoría hombres de clase media, universitarios, citadinos, hispanohablantes, registrando masivamente la vida de comunidades indígenas quichuas, en el corazón de Los Andes, a las que llegaban un día cargados de buenos propósitos y se alejaban otro para quizás no volver? El indigenismo escondía no solo las intenciones, loables seguramente, de integrantes de la pequeñoburguesía ecuatoriana con marcada vocación paternalista sino además, y esto quizás sea más difícil de ver, los complejos íntimos de unos realizadores convencidos políticamente pero 
confundidos existencialmente, lo cual es factible de entender en tanto se trata de hombres, salvo alguna excepción, que no estaban contentos con su suerte y buscaban una vida distinta de la que vivían. Sin embargo, dicha inconformidad no es enfrentada a través de la elaboración narrativa de unos autores que persiguen un deseo insatisfecho sino que se esconde detrás de la escritura política de unos militantes (Barthes, 2010). El psicoanálisis de aquellas obras de los años ochenta nos permitiría entrever, quizás, una respuesta del por qué sus autores proyectaban en otros, en los indígenas entendidos como un objeto de deseo político, una noción o "esencia" del deber ser, más aun cuando, con el pasar de los años, masivamente aquellos autores abandonan la militancia de izquierda para devenir, muchos de ellos, popes de la producción publicitaria ¿El compromiso político fue una moda o simple locura de juventud?

Ante la ausencia de una clase obrera propia de una realidad industrial, como mandaban los manuales de la revolución que debía hacerse, que llegaban desde atrás de la cortina de hierro de la lejana Europa del este, en Los Andes se buscó en los indígenas al sujeto social del cambio aunque estos últimos ni se enterasen del anhelo de unos cineastas políticos muchos de los cuales, en efecto, militaban entonces en partidos de izquierda o de extrema izquierda. Al visibilizar las condiciones feudales o esclavistas de vida de la mayoría indígena, que se expresa económicamente en la tardía existencia del huasipungo ${ }^{6}$ incluso a finales del siglo XX, se dio paso en repetidas ocasiones a producciones panfletarias que se estrellaron, finalmente, ante las contradicciones y límites de sus realizadores y las circunstancias que los envolvían.

La obra cumbre del período, Los hieleros del Chimborazo (1980), refleja precisamente los elementos centrales de esta problemática relación entre aquellos autores urbanos y mestizos con sus objetos de deseo político y artístico: fascinación por el paisaje, idealización de los personajes e imposibilidad de comunicación entre dos mundos colindantes, opuestos, separados por una histórica y fundacional frontera social, cultural y lingüística invisible y determinante, presente entre criollos "mishus" (los realizadores) e indígenas (los personajes). De cualquier forma, esta obra de Igor y Gustavo Guayasamín conserva una descarnada honestidad y potencia artística que le ha permitido superar la prueba del paso del tiempo, más allá de la densidad de su carga política, gracias a un espesor filosófico, simbólico, estético y existencial que nace de la extraordinaria presencia fotográfica tanto como de la historia de vida de sus personajes, así como por la potencia de la puesta en escena del documental que revela, casi sin querer, la crisis identitaria de sus autores.

Durante el período mencionado se produce una variedad de obras que abordan diversos géneros y temáticas. Las hay de reconstrucción histórica, como Montonera (1982), de Gustavo Corral, o costumbristas, como Una araña en el rincón (1982) o Un ataúd abandonado (1981), las dos de Edgar Cevallos, entre otras. Pero es el realismo social de denuncia el género que comanda el estilo generacional, lo cual es visible también en los títulos mencionados, siendo el indigenismo la vertiente dominante de la etapa.

De cualquier forma, me interesa subrayar, ante todo, el espíritu gregario presente en la comunidad de cineastas durante aquellos años, el cual los hace actuar colectivamente bajo una misma consigna política en pos de un objetivo común, unidos como una suerte de comunidad práctica (Adler, 2008) con patrones de acción y creencias similares desde donde estructuran su experiencia como individuos y como parte de un todo. Me interesa hacer 
alusión a dicho gregarismo porque aquel espíritu y forma de actuar colectivamente reaparecería años después tras aprobarse la primera ley de cine de Ecuador, ya no bajo el mandato o lineamiento de una consigna política, sino como manifestación de una hedonista necesidad autobiográfica por parte de un conjunto de cineastas ecuatorianos igualmente pequeñoburgueses, de estratos medios y altos.

Aplicado en biología el concepto de gregario identifica animales o seres que viven en rebaños o manadas y que responden a impulsos instintivos automáticos. Socialmente la utilización del concepto es más compleja pues para algunos autores, como el filósofo positivista Bertrand Rusell, se debe partir de la idea de que las pasiones son la fuerza motriz de todas las acciones humanas (Russell, 2002) y por lo tanto los seres humanos no somos completamente gregarios, como las hormigas, pero tampoco completamente solitarios, como los tigres o los leones. Según Rusell somos animales semi-gregarios (Russell, 2010). De cualquier forma el adjetivo permite caracterizar conductas colectivas que en nuestro caso operan a través de resortes idiosincráticos muy perseverantes que se encuentran profundamente arraigados en nuestra sociedad pues, aunque en los ochenta el espejo del cineasta militante refleja el rostro de un indígena y en el cine más reciente el espejo devuelve el rostro de un adolescente, o de un adulto joven pequeñoburgués problematizado, las características del comportamiento colectivo en los dos momentos son resultado de un mismo capital cultural (Bourdieu, 2005) que hunde sus raíces en el espíritu y la herencia histórica de la sociedad colonial ecuatoriana. Las temáticas son distintas en cada momento pero la mecánica que conduce a la actuación colectiva, estructurando un gregarismo primario, base de la actuación grupal, se construye desde una plataforma social y cultural compartida por las dos generaciones.

El desplazamiento se produce entre una y otra porque si en los ochenta la corriente principal hacía que el autor hable veladamente de sí mismo y sus vacíos a través del retrato indigenista, propio del realismo social de denuncia que busca transformar una sociedad, en el cine más reciente, al que llamaré post-indigenista para abrir una línea de continuidad entre las dos etapas, el autor ya no usa más la máscara de un sujeto social distinto a través de la representación, como los indígenas, sino que habla sobre sí mismo sin ambages a través de personajes que refieren directamente a la biografía del autor. Salta a la vista en primer lugar que existen pocos trazos de escritura política de denuncia en estas nuevas propuestas y, a su vez, que la mayoría de ellas se ven presas del dispositivo formal que utilizan, deviniendo en extremo frívolas o superficiales.

Toda máscara implica una dualidad, dice Octavio Paz (1950) y la consecuencia directa de esas dos caras son seres más solitarios e individualistas, en principio menos gregarios. Pero esa es una de las contradicciones e ironías del proceso. El aire de familia encuentra su raíz en un impulso gregario de raíz andina del cual emana una tendencia recurrente a actuar colectivamente siguiendo una corriente, moda o tendencia principal dominante. Se lo ve con claridad en los dos momentos señalados. Y lo dicho se refuerza por la atmósfera intelectual y cultural de la ciudad de Quito, pues si bien el cine ecuatoriano se nutre de autores de diversos rincones de la geografía nacional como Loja, Cuenca, Guayaquil, Guaranda, Portoviejo o Manta, entre otras ciudades, así como de gente de otras nacionalidades, es el habitus ${ }^{7}$ de la capital ecuatoriana el que cubre bajo su manto este aire de familia, y eso se refleja notablemente en la respuesta del público en salas comerciales: la supervivencia 
en cartelera de los filmes nacionales depende centralmente del comportamiento del público quiteño, pues las salas del resto del país, muy especialmente de Guayaquil, ciudad que cuenta con casi la mitad del mercado de pantallas, muestran tradicionalmente una respuesta pobre para el cine de producción nacional. Ahora, dicho fenómeno responde también tanto a la vieja disputa regionalista existente entre puerto y capital, como a los hábitos de consumo cultural algo más cosmopolitas en Quito y mucho más colonizados por la gran industria hegemónica en Guayaquil.

De cualquier forma, más allá de que el mercado quiteño registre serios altibajos de comportamiento, llegando a picos de más de 300.000 espectadores para el cine nacional entre 2011 y 2012, la coincidencia entre autores y público nos habla también de ese capital cultural compartido, desde el cual se acoge inicialmente con entusiasmo al cine autobiográfico que presenta relatos sobre la niñez o adolescencia de la clase media y de la burguesía ecuatoriana en los años setenta, ochenta o noventa. Es decir, mientras el "cine de indios" de los años ochenta no era aceptado en salas, el cine de adolescentes de principios del siglo veintiuno es calurosamente recibido, en un inicio, para luego saturar la bienvenida ante la pérdida de novedad debido a la repetición, familiaridad e insistencia de las propuestas. De cualquier forma el cine indigenista de los años ochenta dejó una herencia clave para los documentalistas ecuatorianos de inicios del siglo veintiuno, una escuela, una pequeña tradición ${ }^{8}$. No así el cine de ficción que se encuentra huérfano de referencias locales ${ }^{9}$ y quizás por eso reproduce con mayor insistencia extravíos que son propios de un proceso de búsqueda.

Al final de aquel primer periodo, tras la muerte de Roldós y la eliminación de los débiles estímulos existentes por parte del nuevo gobierno heredero del accidente aviatorio, tiene lugar un declive importante de la producción. Hacia finales de la década de los ochenta se registran las últimas expresiones de importancia de la corriente realista social con el estreno del largometraje La Tigra (1990), de Camilo Luzuriaga, realizado bajo el paraguas del costumbrismo. Posteriormente, durante los años noventa, la sequía sería brutal. El país entra en una etapa de desmantelamiento del estado y no se cuenta con políticas de estímulo de ningún tipo. Sólo a finales de la década e inicios del nuevo milenio se registran novedades: hacia 1999 por primera vez coexisten en cartelera dos títulos nacionales de largometrajes de ficción: Sueños en la mitad del mundo, de Carlos Naranjo y Ratas, ratones y rateros, ópera prima de Sebastián Cordero, siendo esta la obra que inaugura el período más prolífico del cine ecuatoriano e impone un tipo de escritura cinematográfica que, como he señalado, se vería fagocitada a sí misma casi veinte años después.

La dinámica que se produce tras aquellos estrenos de Cordero y Naranjo sería clave para que, en el año 2006, se apruebe por primera vez una ley de cine en Ecuador dando lugar a una verdadera "primavera audiovisual" facilitada por la llegada de Rafael Correa al poder el año 2007. Así, durante una década, se sentaron las bases para el más largo período, durante la historia republicana, de aplicación de políticas públicas de apoyo para el cine y el audiovisual ecuatorianos. Basado en gran medida por el impulso normativo, institucional y legal que se hace posible a la luz de la Constitución de Montecristi. 


\section{El aire de familia, pequeño colegio invisible en Los Andes ${ }^{10}$}

Más allá de que no exista una intencionalidad explícita a través de un mecanismo estructurado de intercambio de ideas entre las y los cineastas ecuatorianos, sin contar con el que posibilita el sistema social de un medio endogámico por su naturaleza histórica, las similitudes de forma y fondo en casi una veintena de filmes de ficción estrenados durante esta "primavera audiovisual" resultan evidentes ${ }^{11}$ en primer lugar por la ya señalada vocación hedonista que, si bien refleja cierta honestidad autoral, revela como principal característica política precisamente su desinterés por lo político. Eso frivoliza las obras y hace que éstas aparezcan, en su mayoría, carentes de un contexto que explique y sitúe a los personajes en relación a la historia de un país fracturado en su diversidad.

La familiaridad de este cine de nicho pequeñoburgués salta a la vista, en primer lugar, a nivel de argumentos. Los relatos e historias abordan la niñez o adolescencia de personajes urbanos de estratos medios o altos durante los años setenta, ochenta, noventa e inicios del siglo XXI en Ecuador y son, como se ve en la lista, tan numerosos que se podría hacer un ciclo dedicado exclusivamente a la configuración psicológica y cultural de esa clase social en Ecuador, partiendo de la premisa de que ésta aparece representada desde una suerte de burbuja donde la interacción con el mundo exterior, por ejemplo con la realidad indígena o afro, sea esta urbana o rural, o con las diversidades en general, es casi nula. Esto ha sido erróneamente caracterizado por algunos como un problema de auto-referencialidad, cuando es sencilla autobiografía de personajes a los que les falta vivir, dicho sea de paso. Es decir, no hay metalenguaje de por medio. No estamos frente a autores que dialogan con otras obras de su autoría, lo cual activaría la autorreferencia a nivel del lenguaje o de la escritura. Vemos, a la vez, que el impulso autobiográfico opera tanto en la ficción como en el documental, pero en este último género aparece un factor de credibilidad y empatía mucho mayor que en el primero, por el lazo y compromiso existente entre autores e historias narradas. En el conjunto de películas de ficción señaladas se aborda colectivamente a la pequeño-burguesía ecuatoriana porque la mayoría de cineastas nacionales provienen de ella. En términos de Bourdieu se puede decir que el propio capital social y cultural (Bourdieu y Passeron, 1996) de los cineastas ecuatorianos opera como base para provocar este parentesco estético y temático entre obras de distintos autores.

El emplazamiento temporal de casi todas las historias coincide con el período de vida de las y los directores. Entre los protagonistas hay niños/as de entre 7 y 10 años, adultos jóvenes, de entre 25 y 35 años, por ahí alguno/a de 40, que, colectivamente, autorretratan a sus autores. En las historias se presenta, de forma casi unánime, un marco familiar tradicional apegado a distintos niveles de religiosidad y formalismo social, ya sea que éste se muestre inflexible o en crisis; mientras que los conflictos narrativos involucran, sea en primer o en segundo plano, una problemática relación intergeneracional, generalmente entre un mundo adulto que no comprende al joven en transición. Los entornos de las historias son urbanos. De hecho, en todos los casos mencionados se trata de personajes urbanos aunque algunos escapen o vivan sus historias en la ruralidad provista por la hacienda, la selva o la finca familiar. Los ambientes colegiales o escolares se repiten y el tránsito por estos espacios resulta determinante y problemático en la biografía de los personajes, ya sea porque buscan ser aceptados en ellos o porque, años después, se reencuentran con viejos 
compañeros de estudio y eso provoca una crisis de auto identificación o, en suma, de crecimiento y madurez. Precisamente varias historias giran en torno al tránsito de la niñez a la adolescencia o de la adolescencia a la adultez retratando la dificultad de tomar decisiones o simplemente los escollos de crecer y asimilarse al sistema.

Desde un punto de vista estrictamente sociológico el estrato de clase de este cine que se construye, como ha sido dicho, como una cápsula o desde una burbuja con poco o nulo contacto con otras realidades, se deja ver, por ejemplo, en el hecho de que apenas se ocupa, o retrata muy por encima, al mayor trauma social del Ecuador de fin de milenio: la crisis financiera, el feriado bancario y el inédito e histórico éxodo migratorio producto de ello, son hechos sociales que aparecen como lejano telón de fondo de contados títulos ${ }^{12}$. Tan dado a historias intimistas y personales el reciente cine ecuatoriano de ficción frecuenta poco las historias de vida de los migrantes ¿Quizás porque es un fenómeno sobretodo popular, proletario y hasta campesino? Es legítimo preguntarse ¿Por qué hay tan pocas películas de ficción sobre una problemática que cuenta con al menos un millón y medio de ecuatorianos, según cifras oficiales, viviendo fuera del país?

La sucesión de historias caracterizadas por esta atmósfera pequeñoburguesa se produce como un oleaje, una verdadera marejada, que al final inunda el limitado espacio del mercado local disponible para los filmes nacionales. Es por ello que, luego de ver historia tras historia, relato tras relato con pasajes muy familiares y parecidos entre sí, la respuesta y entusiasmo del público decae notablemente. Hoy el sentido común o la percepción generalizada en torno al cine nacional lo ubica bajo una etiqueta que lo iguala todo, como si se tratase de un género en sí mismo. Tampoco se puede olvidar que el público ecuatoriano está colonizado por blockbusters norteamericanos, contra lo cual compite la producción nacional, y que aquello representa el $99 \%$ de lo que consumen un promedio de 14 millones de espectadores por año.

Otro factor evidente en la conformación de este "aire de familia" se hace presente a través de las formas y la estética las cuales se repiten reiteradamente, quizás de manera inevitable pues sucede lo propio con los equipos artísticos y creativos en la dirección de arte, de fotografía o en el montaje de las obras. Es decir, la familiaridad entre estas películas se reconoce no solo por el fondo autobiográfico de las historias, y el tipo de personajes creados, sino también por un estilo y estética similar practicada por las personas que participan de la producción.

Resulta notoria, además, la apuesta generacional por un cine de montaje invisible ${ }^{13}$ (Burch, 2008) pues, salvo contadísimas excepciones ${ }^{14}$, la voluntad narrativa de las obras se plasma en relatos que se desarrollan sin dejar rastro de su escritura, es decir, que no buscan generar ninguna extrañeza en el espectador sino, por el contrario, sumergirlo en un dispositivo dramático imperceptible propio de una narración naturalizada y obturada. Desde esta perspectiva en algunos casos las referencias creativas ni siquiera están en el universo del cine sino de series de televisión norteamericanas, es decir, en referentes estéticos cuya liviandad se asienta, precisamente, en la ausencia de diálogo con la historia del cine, o sea con el lenguaje cinematográfico. Por esta razón resulta notable y llamativo que, a pesar del tiempo transcurrido, la película ecuatoriana de ficción que continúa en la vanguardia de la reflexión estética sobre la imagen en movimiento, por haber arriesgado una mirada sobre 
el hecho cinematográfico como ejercicio de lenguaje y estilo, sigue siendo Entre Marx y una mujer desnuda (1996), de Camilo Luzuriaga.

Resulta especialmente visible, además, en muchos de los títulos señalados la voluntad de hacer un cine superficialmente cosmopolita y esto se traduce en lo que quizás sea el defecto formal más evidente de la mayoría de obras. Hablo de una notoria voluntad por contar cierto tipo de historias que no indagan más allá de las apariencias de sus personajes. Por esta razón resulta evidente la necesidad de arropar los proyectos bajo estructuras del cine industrial, para tratar de suplir a través de la forma defectos o debilidades de fondo. Esto se expresa, por ejemplo, en puestas en escena complicadas, excéntricas o muchas veces pretenciosas que saltan a la vista no por efectivas sino por artificiosas; así como por largas e interminables listas de extras y créditos que evidencian una voluntad de mostrar y hacer patente la factura, la hechura, como un gesto que ansía revelar, a su vez, una modernidad que termina develando, por el contrario, ingenuidades de un cine en construcción. En el fondo la superficialidad trata de suplir la falta de compromiso de un autor con su historia y sus personajes porque, de otra manera, estos alcanzarían mayor profundidad. Con excepciones, el cine ecuatoriano de ficción ha estado más interesado en frecuentar los estilos de moda y en boga en festivales de cine que hacen énfasis en la producción latinoamericana y ha descuidado su compromiso con las historias, con los guiones y con las interpretaciones, desatendiendo así el corazón de la representación fílmica, el lugar donde se construyen los vínculos emotivos, empáticos, racionales e irracionales tanto con públicos masivos como con audiencias más críticas y educadas.

Señalemos, finalmente, una razón estructural que contribuye de forma decisiva a crear este "aire de familia", que se encuentra dentro del proceso mismo de selección de proyectos, sacralizándolo a nivel de políticas de fomento y subsidio público ${ }^{15}$ :

En el afán de cumplir uno de los mandatos morales fundamentales que llevaron a la aprobación de la Ley y la consecuente creación del CNCINE, la cual era aplicar políticas de fomento cinematográfico sin clientelismo y diferenciarse así de las atávicas prácticas de la Casa de la Cultura Ecuatoriana, se adopta el sistema del pitching, ampliamente difundido en el mundo, con el cual ciertamente se obtienen resultados validados y reconocidos socialmente pero que, a su vez, contenían el huevo de la serpiente: se consagraba así la dependencia al sistema internacional de división del trabajo cultural, no por el método en sî́ sino por la dinámica que, inevitablemente, asumen los jurados al constituirse como "comunidades epistémicas" (Adler y Haas; 1992) donde su análisis privilegia un tipo de producción en función de criterios de validación hegemónicos tales como la posible aceptación en festivales de cine. Entonces resulta inevitable preguntarse ¿Para qué mirada se produce? ¿Cómo se construye esa mirada? ${ }^{16}$

Estas "comunidades epistémicas" constituidas espontáneamente al interior de los jurados de selección, han privilegiado un cierto tipo de proyectos que he tratado de describir aquí y que el cineasta Camilo Luzuriaga, decano del cine nacional, ha caracterizado así: 
Frente al público, frente a la crítica y la opinión pública, el cine ecuatoriano se percibe como quiteño, no se percibe como 'nacional'. El cine ecuatoriano es castellano, urbano europeizado y anglo norteamericanizado. No es kichwa, no es shuar, no es afroecuatoriano. El cine ecuatoriano es de adolescentes que juegan a ser grandes, hecho para grandes que juegan a ser adolescentes. No es para infantes, no es para niños, no es para prepúberes, no es para púberes, no es para sordos, no es para ciegos. No es para toda la familia"17.

\section{Conclusiones}

Si bien los retos para la escena cultural de un país fracturado en su diversidad implican desmontar estructuras concebidas como auténticas camisas de fuerza, una primera conclusión quiere ser optimista frente a todo lo dicho porque, una vez identificado este recorrido del cine ecuatoriano, podemos proyectar ideas y orientar la reflexión en al menos dos direcciones: a nivel estético, de las formas y el lenguaje; y a nivel de las historias. Hablamos por un lado de la necesaria profundización de un diálogo posible y urgente entre los creadores nacionales y el centenario lenguaje cinematográfico en sí mismo. Esto implica pensar no solo en las referencias existentes desde la gran industria y desde representaciones más abiertas y vigorosas propias del cine de autor o experimental, sino, además, en la difícil dinámica que opera entre las cinematografías hegemónicas y las emergentes o marginales. Y en cuanto a las historias claramente se debe superar el ombliguismo pequeñoburgués dominante, carente de sustrato político, para abordar temáticas más amplias, propias de la diversidad humana, histórica, cultural y social que nos caracteriza como sociedad, la cual demanda lecturas que permitan la creación de una narrativa más incluyente y que asuma riesgos a través de la representación cinematográfica. Los desafíos del cine no sólo ecuatoriano, sino latinoamericano en general, están a nivel de la dramaturgia, pues es ahí donde resulta necesario encontrar otras formas de contar que pongan en juego la forma hegemónica de construir el relato cinematográfico porque lo que está en disputa, al final, es la subjetividad de las audiencias.

Podemos suponer que el histórico aislamiento de Ecuador y la limitada exposición de sus artistas, en general, presionó en la adopción de un tipo de cine que buscara mimetizarse con formas sacramentadas a nivel latinoamericano durante las primeras décadas del siglo XXI, para así integrarnos y ser parte del grupo ¿Perdimos con la Ley de 2006, la oportunidad histórica de inventar algo completamente nuevo? Probablemente. La adopción de la ley de cine en el país abrió una etapa de optimismo efervescente que, en alguna medida, nos hizo creer que con ese imperfecto instrumento legal sería suficiente, no solo para competir con la gran industria hegemónica, sino para construir una cinematografía que iba a seducir al mundo entero. Evidentemente la herramienta fue útil para empezar a caminar, solamente y eso, a la larga, permitirá que en algún momento se alcance la maestría y la madurez necesarias en el dominio de un arte y un lenguaje extremadamente complejos. La cinematografía ecuatoriana se comporta generacionalmente de acuerdo a patrones sociales y culturales de tipo gregario que marcan con claridad tendencias o corrientes 
principales, modas, que son adoptadas en grupo por los y las cineastas en conjunto y eso se ve tanto en los años ochenta, durante el auge del cine indigenista, cuanto en el cine de la primavera audiovisual tras la ley de cine de 2006, lo cual se explica en parte por el capital cultural (Bourdieu, 2005) compartido por dichos cineastas que provienen, generacional y mayoritariamente de estratos medios y urbanos de la sociedad en los dos casos.

En Ecuador el género documental goza de mayor fortaleza y tiene mejor recorrido que el cine de ficción por razones fundamentalmente estructurales. Siendo trascendente la elaboración discursiva a favor de la memoria social y reconociendo el enorme e histórico impacto de estos relatos dentro del imaginario colectivo, hasta cierto punto impensado, el impulso autobiográfico presente en la mayoría de películas documentales las conduce también dentro de una corriente principal en la que se echan de menos mayores riesgos formales y estéticos, dada la ortodoxia de las propuestas, que reflejen apuestas por un diálogo más activo e interactivo, en lo formal y en lo dramatúrgico, con referentes cinematográficos más amplios y universales.

La expresión cinematográfica de los anhelos y utopías de la clase media ecuatoriana inevitablemente conduce a la creación de estereotipos, reflejados en hechos triviales y en banalidades individualistas de sus personajes. Ese universo simbólico ha dominado los relatos durante las dos etapas descritas en el texto. El desafío de los autores del cine nacional, hombres y mujeres, es trascenderse a sí mismos, utilizando aquellas vocaciones autobiográficas para construir relatos más complejos y estructurados sobre la diversidad que nos marca como pueblo. Necesariamente, se hará camino al andar.

\section{Notas}

1. Gramsci (1924) se refería a ella como la clase "eternamente oscilante entre el capitalismo y el proletariado", graficando el espacio para dramas arribistas o seductores que alternativamente la caracterizan; mientras Marx y Engels (1938) decían que: "La pequeña burguesía democrática está muy lejos de desear la transformación de toda la sociedad; su finalidad tiende únicamente a producir los cambios en las condiciones sociales que puedan hacer su vida en la sociedad actual más confortable y provechosa". (...) "aspiran a corromper a la clase trabajadora con la tranquilidad, y así adormecer su espíritu revolucionario con concesiones y comodidades pasajeras". Luego añadieron en "La lucha de clases en Francia" (1938) que: "El capital acosa a esta clase [la pequeña burguesía] principalmente como acreedor; por eso ella exige instituciones de crédito. La aplasta con la competencia, por eso ella exige asociaciones apoyadas por el Estado. Tiene superioridad en la lucha, a causa de la concentración de capital; por eso ella exige impuestos progresivos, restricciones a la herencia, centralización de grandes obras en manos del Estado y otras medidas que contengan por la fuerza el incremento del capital". Tal disputa del siglo XIX europeo ilustra muy gráficamente los problemas de esta clase en las sociedades latinoamericanas del siglo XX y XXI y particularmente de la pequeño burguesía ecuatoriana. 2. Como corriente de pensamiento que pone en valor lo indígena, cuestionando y denunciando la discriminación y la opresión bajo la cual se sometió a los pueblos nativos desde 
la colonia, el indigenismo toma fuerza a inicios del siglo XX en América Latina y decae a partir de los años 70, cuando las limitaciones y contradicciones paternalistas de una corriente que, finalmente, buscaba "salvar al indio de sí mismo" (Bonfil, 1970) resultan evidentes. En Ecuador, a raíz del levantamiento y movilización social de 1990, que transforma al movimiento indígena en sujeto político histórico y activo, el indigenismo en las artes (como acción política de autores no indígenas) pierde, definitivamente, toda razón de ser. 3. Entrevista del autor a Jaime Cuesta, 1992.

4. Ernesto Albán Mosquera (1912-1984) actor y comediante originario de la ciudad de Ambato, creador del personaje considerado no sólo su alter ego sino un símbolo de la quiteñidad o del "chulla quiteño": Evaristo Corral y Chancleta. Tiene en Ecuador una importancia equivalente a la de Niní Marshall en Argentina, Tres Patines en Cuba o la de Cantinflas en México.

5. Entrevista del autor a Igor Guayasamín, 1992.

6. El arcaico sistema de explotación así denominado, que en 1934 diera título a la novela homónima de Jorge Icaza, cumbre literaria del movimiento indigenista, se encuentra en el corazón del feudalismo colonial andino gracias al establecimiento de un "acuerdo" entre hacendados e indígenas peones a través del cual se daba la "cesión" de parcelas de terreno para su usufructo a cambio de la mano de obra gratuita y perpetua de millones de indígenas. Esta ignominiosa forma de acumulación esclavista del mundo colonial se mantuvo presente casi hasta finales del siglo XX en Ecuador.

7. Bourdieu lo define como "los sistemas perdurables y transables de esquemas de percepción, apreciación y acción que resultan de la institución de lo social en el cuerpo (o en los individuos biológicos)" (Bourdieu y Wacquant, 2005, p. 181). Es la forma cómo el agente entiende sus comportamientos a través de unas "estructuras estructurantes estructuradas" que operan como un conjunto de esquemas generativos a partir de los cuales las personas perciben y comprenden el mundo y, desde esa comprensión, actúan en él.

8. La mayoritaria presencia de la forma de producción documental, a lo largo de la intermitente historia del cine ecuatoriano, se explica también y fundamentalmente por sus menores necesidades presupuestarias, así como por sus equipos técnicos y humanos mucho más livianos, lo cual facilita, sin duda, su articulación y puesta en marcha. Esto ha terminado por generar en Ecuador un mayor estado de madurez del género documental que de la ficción porque existe cierto dominio de ese "saber hacer". Adicionalmente, el punto de vista y la perspectiva dominante en el género documental expresa un compromiso muy cercano entre autor y temática, cosa que en la ficción resulta, por el contrario, la evidencia de un ejercicio muchas veces vacío y superfluo.

9. A excepción, quizás, de Sebastián Cordero cuya influencia puede rastrearse de distintas maneras en el cine ecuatoriano a lo largo y ancho de estos años y muy especialmente gracias a la estética de su primer largometraje. Su influencia, en efecto, refleja una curva que se abre con Ratas, ratones y rateros (1999) y se cierra, por ahora, con Sin muertos no hay carnaval (2016), sexto largometraje de ficción de Cordero. Dicha curva arranca de forma ascendente con la irrupción de un lenguaje y estilo que sorprende, renueva y sacude la pequeña cinematografía nacional, poniéndola en el mapa de festivales internacionales, mientras que la parte descendente de la curva marca un claro agotamiento e incluso una crisis creativa del cineasta en su sexto film, el cual descubre los límites de su escritura 
fílmica pues dicha propuesta resulta repetitiva y sin sorpresa. Es curioso que Cordero, siendo el cineasta más influyente de Ecuador durante estos años, no participe plenamente de este "aire de familia" por el eclecticismo de su obra ya que, a diferencia de sus colegas, no aborda abiertamente los dramas y conflictos de su propia clase, sino que se muestra interesado e incluso fascinado por personajes que están en las antípodas de sí mismo. Eso ha terminado de agotar, por asfixia, su propio estilo.

10. Colegio invisible es un concepto decimonónico de origen anglosajón que se encuentra en la base de la posterior renovación de Academias y Sociedades Científicas y que se encuentra, también, en la raíz del concepto de Comunidad Epistémica (Hass, 1992).

11. Una lista mínima y no excluyente de películas de ficción post 2006 que comparten el "aire de familia" comprende a: Esas no son penas (2007), Daniel Andrade \& Anahí Hoenesein. Cuando me toque a mi (2008), Víctor Arregui. Los canallas (2009), Jorge Fegan, Nataly Valencia et. al. Impulso (2009), Mateo Herrera. En el nombre de la hija (2011), Tania Hermida. A tus espaldas (2011), Tito Jara. Mono con gallinas (2012), Alfredo León. Sin otoño sin primavera (2012), Iván Mora. La llamada (2012), David Nieto. Mejor no hablar de ciertas cosas (2012), Javier Andrade. A estas alturas de la vida (2013), Alex Cisneros y Manuel Calisto. El facilitador (2013), Víctor Arregui. Saudade (2014), Juan Carlos Donoso. Feriado (2014), Diego Araujo. Ochentaisiete (2014), Daniel Andrade \& Anahí Hoenesein. UIO, sácame a pasear (2016), Micaela Rueda. Instantánea (2016), Catalina Arango. Tan distintos (2016), Pablo Arturo Suárez. Chuquiragua (2016), Mateo Herrera. Alba (2016), Ana Cristina Barragán. (Esta última película requiere una consideración especial pues si bien forma parte del conjunto de obras que retratan la vida de la pequeñoburguesía ecuatoriana, se distingue por el profundo compromiso existente entre la autora y la historia narrada, lo cual se refleja en un guion que se despliega estructuradamente en capas de distinto espesor narrativo y dramático, así como por las formidables interpretaciones las cuales, en conjunto, otorgan a Alba una sensación de verdad distinta a los demás títulos citados). 12. El film de ficción emblemático del período que aborda abierta y directamente el tema de la migración es Prometeo Deportado (2010), cuya génesis es resultado de la experiencia de vida de su director, Fernando Mieles, quien vivió en carne propia el drama de la deportación desde Europa.

13. Una definición popularizada de montaje clásico o invisible nos dice que es aquel que cuenta los hechos bien cronológicamente o haciendo saltos tanto al futuro (flash-forward) como al pasado (flash-back), pero siempre estructurándose con la idea de dotar a la historia de una forma narrativa que transcurra de forma transparente ante el espectador. Referencia Disponible en:

14. https://cursotecnicoav.wikispaces.com/file/view/TEOR\%C3\%8DAS+DEL+MONTAJE. pdf

15. Sea porque sus autores buscan caminos abiertamente individuales y rehúyen la posibilidad de hacer parte de una cofradía o porque las excepciones confirman la regla, hay obras que escapan de la corriente principal del cine ecuatoriano reciente. Estas son: Blak Mama (2009), de Miguel Alvear y Patricio Andrade. Más allá de mall (2010), de Miguel Alvear. Silencio en la tierra de los sueños (2014), de Tito Molina. Un secreto en la caja (2016), de Javier Izquierdo, entre otras. Por otra parte, el trabajo de cineastas como Alejandra Cuesta se desarrolla plenamente en el campo experimental. Menciono también experiencias de 
cine comunitario como Santa Elena en Bus (2013) o Vengo volviendo (2015), las dos de Gabriel Páez e Isabel Rodas, entre otros títulos que, por temática y estilo, escapan de dicha corriente principal y, aunque participen de alguna de sus formas, plantean opciones a favor de la diversidad cultural desde un punto de vista comunitario.

16. El presente texto nace de una voluntad autocrítica, desde un punto de vista reflexivo, cualitativo y analítico, porque como Director Ejecutivo del CNCINE (2006-2013) fui, junto a compañeros y compañeras muy comprometidas, responsable de crear las condiciones de posibilidad de lo relatado estructurando un proceso inédito de ayudas a la producción cinematográfica en Ecuador. La selección de los proyectos fue siempre facultad de jurados externos, que actuaban con plena libertad de decisión y que emitían un veredicto inapelable, porque se buscaba evitar el clientelismo y la discrecionalidad, aunque esto terminó articulando una corriente principal a la que se integró colectivamente toda una generación de cineastas ecuatorianos/as.

17. Serrano, Jorge Luis. "Montañas rusas de gozo vano." Chasqui, revista latinoamericana de comunicación. Núm. 132. Cine, política audiovisual y comunicación. Quito. 2016.

18. http://www.eltelegrafo.com.ec/noticias/carton-piedra/34/la-industria-ecuatoriana-delcine-otra-quimera

\section{Referencias Bibliográficas}

Adler, E. (2008). "The Spread of Security Communities: Communities of Practice, SelfRestraint, and NATO's Post-Cold War Transformation", European Journal of International Relations vol 14 No 2 (June 2008), 195-230.

Adler, E. y Hass, P. (1992). "Las Comunidades epistémicas, el orden mundial y la creación de un programa de investigación reflectivo". International Organization, vol. 46, no 1, Knowledge, Power and International Policy Coordination, invierno 1992, ps. 367-390

Barthes, R. (2010). El grado cero de la escritura. Argentina: Editorial Siglo XXI.

Bonfil, G. (1983). “Del indigenismo de la revolución a la antropología crítica”. En La Quiebra política de la antropología social en México (Antología de una polémica). Editores: Andrés Medina y Carlos García Mora. UNAM.

Bourdieu, P. y Wacquant, L. (2005). Una invitación a la sociología reflexiva. Argentina: Editorial Siglo XXI Editores.

Bourdieu, P. y Passeron, J.-C. (1996). La reproducción. Elementos para una teoría del sistema de enseñanza. México: Distribuciones Fontamara.

Burch, N. (2008). Praxis del cine. Madrid: Fundamentos.

Gramsci, A. (1924). La crisis de la pequeña burguesía. Roma: Diario L’Unitá.

Marx, K. (1938). Obras escogidas. Selección de V. Adoratsky. Traducción española de W. Roces. Instituto Marx-Engels-Lenin de Moscú. Barcelona: Ediciones Europa-América.

Paz, O. (1998). El laberinto de la soledad, Postdata y Vuelta a El laberinto de la soledad. Fondo de Cultura Económica de España. S.L. Segunda reimpresión en España.

Russell, B. (2002). Lo mejor de Bertrand Russel. Editado por Robert E. Egner. Edhasa.

Russell, B. (2010). Poder, un nuevo análisis social. España: RBA. 
Serrano, J. L. (2016). “Memoria de una primavera audiovisual”. En Diario El Telégrafo, edición de 8 de febrero de 2016: http://www.eltelegrafo.com.ec/noticias/carton-piedra/34/ memoria-de-una-primavera-audiovisual

Serrano, J. L. (2016). "Montañas rusas de gozo vano". Chasqui, revista latinoamericana de comunicación. Núm. 132. Cine, política audiovisual y comunicación. Quito. 2016.

\begin{abstract}
At the beginning of the 1980s, Ecuadorian cinema experienced a period of intense activity with very political and militant productions made from an indigenist point of view. 26 years later, after the adoption of the country's first cinema law, it would, instead, lead to a cinema without interest in political matters, markedly hedonistic $i$ What do the two moments have in common? That, in both of them, those who dominate the scene are filmmakers from the middle strata, from the Ecuadorian petty bourgeoisie. These authors, mostly men, especially in the first moment, practice in a gregarious way tendencies that mark each generation. The dialogue that appears between the two phases tells us about the social practices that are historically cultivated in a society fractured in its diversity.
\end{abstract}

Keywords: Ecuadorian cinema - Cultural industry - Petty-bourgeois - Gregarism - Communities of practice.

Resumo: No início dos anos 80 o cinema equatoriano registra um período de intensa atividade com produções militantes de corte indigenista. 26 anos depois, quando foi aprovada a primeira lei de cinema do país, daria lugar, pelo contrário, a um cinema de ficção desinteressado pelo político, marcadamente hedonista ¿ $\mathrm{O}$ que têm em comum as duas etapas? Que, tanto em uma como em outra, quem domina a cena são cineastas originários da classe média, da pequena burguesia equatoriana. Estes autores, principalmente homens, especialmente no primeiro momento, praticam de forma gregária modas ou tendências que marcam cada geração. O diálogo que surge entre as duas fases nos fala de práticas sociais que se cultivam historicamente em uma sociedade fraturada em sua diversidade.

Palavras chave: Cinema ecuatoriano - Indústria cultural - Pequeno-burgueses - Gregarismo - Comunidade práctice.

[Las traducciones de los abstracts fueron supervisadas por el autor de cada artículo] 